\title{
Clinical Subjectivation: Anthropologies of Contemporary Biomedical Training
}

\author{
Seth M. Holmes • Angela C. Jenks • Scott Stonington
}

Published online: 7 May 2011

(C) Springer Science+Business Media, LLC 2011

\section{Introduction}

Throughout the 1970s and 1980s, medical anthropologists increasingly turned their attention to the examination of biomedicine as a sociocultural system (see Gordon 1988 and reviews by Gaines and Hahn 1985; Hafferty 2000; Hahn and Kleinman 1983). A significant portion of this study focused on medical education, exploring the ways in which biomedical practitioners-primarily physicians but also nurses and other members of biomedical health care teams-learn both the "art and science" of medicine.

These early studies recognized the central role that clinicians can play not just in care and healing (Kleinman 1980), but also in social control (Fineman 1991; Navarro 1989; Foucault 1980) and the mystification and reproduction of social inequality (Taussig 1980; Singer and Baer 1995; Waitzkin 1986; Scheper-Hughes and Lock 1986). Given the important role of clinicians in navigating interrelationships among uncertainty, suffering, the body, and society, it is essential to understand their roles, actions, motivations, and ethics (cf., Fox 1957, 1980; Kleinman et al. 1997; Foucault 1994). One key way to understand clinicians is to study the process by which they become biomedical professionals.

\section{S. M. Holmes ( $₫)$}

Program in Health and Social Behavior, University of California,

50 University Hall, Berkeley, CA 94720-7360, USA

e-mail: sethmholmes@gmail.com

\section{A. C. Jenks}

Department of Behavioral and Social Sciences, Los Angeles Southwest College, 1600 West Imperial Highway, Los Angeles, CA 90047, USA

\section{S. Stonington}

Department of Anthropology, History and Social Medicine, University of California,

3333 California St, Ste 485, San Francisco, CA 94143-0850, USA 
The articles in this special issue apply anthropological theory and methods to the analysis of contemporary biomedical training, engaging with a number of recent changes in the field of biomedicine and employing recent insights from the field of anthropology. Medical education today must be examined within the context of new emphases on multiculturalism, global health, and health disparities; an increasing concern with standardization and evidence-based medicine; the development of forprofit and managed health care; demographic shifts among health practitioners, most notably the increasing percentage of female medical students; increased recognition within academic medicine of the so-called "hidden curriculum" (Hafferty 1998; DelVecchio Good 1995); and the introduction of various forms of the culture concept itself into medical education.

Given the emerging and novel nature of many of these developments in biomedicine and biomedical training, the articles in this volume draw upon recent study in philosophy, science studies, and anthropology that addresses the role of experts and expert knowledge in contemporary society. While most previous studies on clinical training have focused on socialization, this volume instead shifts the focus onto the production of clinical subjectivities. What kinds of people are formed through contemporary processes of clinical training, and how do these evolving subjects transform health, power, and other aspects of social life?

In this introduction, we present a brief history of theoretical and ethnographic approaches to clinical training, from professional socialization to the medical gaze. We then introduce the papers in this volume, which highlight the contemporary moment in the anthropology of clinical training and the insights into biomedicine that can be gleaned from a renewed approach to expert subjectivities.

\section{Background: Clinical Training as Professional Socialization}

Many of the first social studies of clinical training emphasized that becoming a physician involves more than the acquisition of technical skill and biological knowledge. Medical education also serves as a process of socialization, instilling the norms, values, and behaviors that are accepted by the profession. At a basic level, the socialization process is intimately related to the determination of which individuals belong in the profession and which do not, who should be promoted to the next level, and who should be excluded altogether. The study of socialization, then, is the study of the reproduction of biomedical society (Hahn and Kleinman 1983).

Early examinations of medical education drew on this theoretical orientation closely. While Merton et al. (1957) used a functionalist paradigm to demonstrate the ways in which "the student physician" progressively adopts the professional norms of their professors, Becker et al. (1961) drew on an interactionist model to describe the "boys in white" as active participants in a student culture who, while learning to manage an overwhelming workload, sometimes accept and sometimes resist their own socialization. 
Studies of socialization highlighted the ways in which medical students learn to make a good impression and save face on patient rounds (Klass 1987; Conrad 1988), or how interns and residents learn the behaviors-including the types of errorsthat will allow them to be promoted as surgeons instead of discrediting them and leading to their exclusion from the profession (Bosk 1979). Ultimately, Conrad (1988) argued, the process of medical socialization leads to a shift in identification; while new medical students may identify most strongly with patients, by the end of their training they identify with the "team" of health providers (see Konner 1987) and may even come to see patients as the enemy (see Reilly 1987).

\section{Learning Detachment and the Medical Gaze}

Reflecting on his experiences in medical school, Robert Marion $(1991,262)$ argued that "medical education in the United States today takes people who enter the system filled with humanism and idealism and ultimately forces them to surrender these ideals by the very process that turns them into technically competent and intellectually capable physicians." As they learn professional norms, physicians-intraining also learn to adopt dominant clinical, rather than social, perspectives on disease and illness (Conrad 1988). In the process, they both learn new ways of seeing patients and are simultaneously remade into new types of people.

Many studies of medical education have examined this process through a focus on the psychological and phenomenological aspects of training. Renée Fox and others (1957, 1980; Lief and Fox 1963), for example, drew attention to the learned demeanors and psychological attitudes of medical students, including the need to develop the dynamic equilibrium of "detached concern" and the ability to act in the midst of uncertainty. Rhodes (1991) takes a related theoretical orientation to describe the ways in which medical students and residents come to inhabit the behaviors and attitudes necessary for "emptying beds" in a psychiatric unit. Other scholars (Hafferty 1988, 1991) have focused on the role of particular educational experiences, such as the anatomy lab, in the development of emotional detachment among medical students. Hafferty (1991) emphasizes that, through the experience of cadaver dissection, students not only learn to see bodies (and by extension patients) as technical objects, but also begin to reimagine themselves and their own futures.

Many of these studies were critical of the process of medical education, emphasizing the way the training process can diminish students' sense of compassion, empathy, and "care" for patients (Conrad 1988). Increasingly, scholars and professionals called for reforms in medical education that would produce more humanistic physicians (AAMC 1984; Bok 1984; Eisenberg 1984; see DelVecchio Good and Good 1989). At the same time, this study opened the door to a theoretical interest in the subjectivity of clinical students.

Ethnographic studies by Good and DelVecchio Good (e.g., DelVecchio Good 1995; DelVecchio Good and Good 1989, 1993) and Davenport (2000) explicitly considered two aspects of trainee subjectivity: the internal phenomenological experience of the student and the development of an external medical gaze (Foucault 1994). DelVecchio Good and Good analyze the introduction of the "New 
Pathway" at Harvard, one of the early case-based curricular reforms in biomedicine. They describe ways in which medical students are socialized into proper professional behaviors and techniques while learning to prioritize "competence" over "caring." In addition, they analyze the means by which biomedical reductionism refashions the patient as a body, an object to be diagnosed, and refashions the boundaries of the trainee in relation to that object through the crossing of intimacy taboos in the sexual history and the physical exam. Davenport presents the struggle between two kinds of clinical gaze at work in a homeless clinic, the reductionist biomedical gaze and the gaze of "witnessing" the suffering of the human patient. She considers both the experiences of the students and the complex and uneven development of their clinical gaze(s).

While much of the anthropology of clinical training to date considers the outward clinical gaze inherent to Foucault's conception of subjectivity, it leaves out a serious consideration of the inward gaze, the processes of self-formation. The more recent emphasis on phenomenology has contributed an understanding of the experience of training, of the responses and emotions produced by an external socialization process and opens the door for a more serious analysis of the ways that clinicians internally craft themselves.

\section{Conclusion: The Production of Subjectivity in Biomedical Education}

Foucault considers the production of the human subject in two primary ways that are especially helpful to the analysis of clinical training (1984). The first was usefully employed by studies such as those by DelVecchio Good, Good, and Davenport. In The Birth of the Clinic, Foucault analyzes the ways in which the clinician comes to be able to see with a particular outward gaze, to see a person as a patient-less as a social, human being with a social voice and more as a body to be analyzed, probed and investigated to discover hidden physical truths (1994). The question, "what is the matter with you?" is replaced by "where does it hurt?" (Foucault 1994). This clinical subjectivity inheres the "objectivation" (1984) of the patient body and, therein, the possibility of positivist science (1994).

But another primary focus for Foucault, equally helpful though less extensively employed thus far in the analysis of clinical training, appears in The Care of the Self (1986). In this book, he describes the ways in which — through the fields of sexuality and ethics-human subjects turn their gazes inward, becoming objects to themselves, objects that can be crafted through practices of self-transformation. He calls this the "'cultivation of the self,' wherein the relations of oneself to oneself [are] intensified and valorized" $(1986,43)$. Combining the two foci, Foucault uses the term "subjectivation" to denote the production of human subjects with dual outward and inward gazes (1984).

The articles in this volume build on earlier examinations of medical education to offer ethnographic and theoretical considerations of the production of the professional clinical subject in diverse training settings, including medical school (Holmes and Ponte, Taylor), dental school (Rivkin-Fish), nursing practice (Pine), 
cultural competency training (Jenks, Shaw and Armin), global health rotations (Brada), and health development programs (Stonington). Many of them analyze clinical sites outside of the elite medical schools historically emphasized in anthropologies of clinical training. Each article focuses on the kinds of health professionals who emerge or are expected to emerge from recent changes in medical training, such as increasing recognition of cultural diversity, global health, and health disparities (Jenks, Shaw and Armin, Rivkin-Fish, Brada); efforts to manage emotion rather than become detached from it (Stonington, Taylor); and a focus on the standardization of training and its power dynamics (Holmes and Ponte, Pine). Through these diverse sites, each article demonstrates how the outward objectivation of the patient and the internal objectivation of the self are inherently linked.

This collection of articles indicates that clinical trainees are not simply socialized and malleable, but are also active subjects who make choices, resist subjugation, accommodate power differentials, and use techniques to actively craft themselves internally throughout the process of becoming a new kind of professional. Some of the articles (Pine, Holmes and Ponte) bring to the fore the fact that, as Das notes, "the experience of becoming a subject is linked to the experience of subjugation in important ways" $(2007,59)$. Power and its production of resistance (Foucault 1980) are inherent to the process of subjectivation. As a whole, the papers ask: how are trainees pushing back or dialectically crafting the field that is simultaneously crafting them?

Stonington describes the emergence of new spiritual movements in the Thai public health system. These movements propose a new concept of "end of life," an interval of time that provides the opportunity for clinicians and patients to craft inner wisdom by facing suffering. As opposed to most clinical training that builds inner states to hone the outward clinical gaze, these movements invert this relationship, teaching trainees to gaze outward to craft a particular kind of inner self.

Taylor examines the increasing use of simulated patients in medical education. The simulations she describes are a specific technology of subjectivation, in which a "real" but "not too real" simulation of suffering allows students to imagine themselves into realistic internal states (shock, fear, nausea, etc.) that they use to craft appropriate responses as healers.

Holmes and Ponte analyze the medical student patient presentation as a narrative technology that disciplines uncertainty in three primary sites. Through this technology, the chaos of patient experience is transformed into a recognizable clinical case, the indeterminate identity of the trainee is reshaped into that of a future physician, and the uncertainty of science is refashioned into a universal metanarrative.

Rivkin-Fish examines how dental education programs that provide health care services to the poor may unwittingly position students to reproduce the misrecognition of power inherent in America's market-based health care system. Dental students are trained in such a way that they can no longer see the macro political and economic structures producing the suffering of their dental patients, but rather end up inadvertently blaming their patients for their suffering. 
Pine examines the recent increase in health information technology, such as the electronic medical record, as a form of simultaneous standardization of health care and control of the nurse as feminized worker. She demonstrates the double-bind in which contemporary nurses find themselves as well as the ways in which they enthusiastically adopt and simultaneously resist this technology.

Jenks examines efforts to produce "culturally competent" health providers, arguing that, as training efforts move beyond essentialized approaches to culture, they shift attention from a social to an individual understanding of difference. As trainees work to become more "openminded," they may lose the perspective needed to critique the social production of health inequality.

Shaw and Armin also examine the development of cultural competency training methods, exploring the ways in which health professionals are encouraged and expected to engage in "ethical self-fashioning." As the study of cultural competence is shifted to individual providers, it can become a new form of governance.

Brada examines the emerging concept of "global health" in medical training, practice, and policy. Brada uses a linguistic lens to show that this new concept is less an orientation to geography than a technology of subjectivation that structures expertise and morality.

The study of the production of clinical subjectivity through the process of biomedical training is especially important today, given the self-consciously multicultural and global nature of contemporary clinical training. These new goals and contexts of training necessitate different forms of subjectivation and involve new forms of resistance and accommodation. Through this collection, we hope to shed light on what it means to be a biomedical professional, a body, and a human subject in the contemporary world.

\section{References}

American Association of Medical Colleges (AAMC)

1984 Physicians for the Twenty-First Century: The GREP Report. Washington, DC: American Association of Medical Colleges.

Becker, H.S., B. Geer, E.C. Hughes, and A. Strauss

1961 Boys in White: Student Culture in Medical School. Chicago: University of Chicago Press.

Bok, Derek

1984 Needed: a New Way to Train Doctors. Harvard Magazine 96(32-43): 70-71.

Bosk, C.A.

1979 Forgive and Remember: Managing Medical Failure. Chicago: University of Chicago Press.

Conrad, Peter

1988 Learning to Doctor: reflections on Recent Accounts of the Medical School Years. Journal of Health and Social Behavior 29(4): 323-332.

Das, Veena

2007 Life and Words: Violence and the Descent into the Ordinary. Berkeley: University of California Press.

Davenport, Beverly

2000 Witnessing and the Medical Gaze: how Medical Students Learn to See at a Free Clinic for the Homeless. Medical Anthropology Quarterly 14(3): 310-327.

DelVecchio Good, Mary-Jo

1995 American Medicine: The Quest for Competence. Berkeley: University of California Press. 
DelVecchio Good, Mary-Jo, and Byron J. Good

1989 Disabling Practitioners: hazards of Learning to be a Doctor in American Medical Education. American Journal of Orthopsychiatry 59(2): 303-312.

Eisenberg, Leon

1984 Rudolf Ludwig Karl Virchow, Where are You Now That We Need You? American Journal of Medicine 77: 524-532.

Fineman, Norman

1991 The Social Construction of Noncompliance: a Study of Health Care and Social Service Providers in Everyday Practice. Sociology of Health and Illness 13(3): 354-374.

Foucault, Michel

1980 The History of Sexuality. Volume 1: An Introduction New York: Vintage Books.

1984 "Foucault" [A Retrospective on the History of Sexuality Published in Dictionnaire des Philosophes]. Electronic document, http://foucault.info/foucault/biography.html, accessed March 20, 2011.

1986 The History of Sexuality. Volume 3: The Care of the Self New York: Vintage Books.

1994 The Birth of the Clinic. New York: Vintage Books.

Fox, Renée

1957 Training for Uncertainty. In The Student Physician. R. Merton, G. Reader, and P. Kendall, eds., pp. 207-241. Cambridge: Harvard University Press.

1980 The Evolution of Medical Uncertainty. Milbank Memorial Fund Quarterly/Health and Society 58(1): $1-49$.

Gaines, Atwood, and Robert Hahn

1985 Among the Physicians: Encounter, Exchange and Transformation. In Physicians of Western Medicine: Anthropological Approaches to Theory and Practice. Robert Hahn and Atwood Gaines, eds. Dordrecht: Kluwer Academic Publishers.

Good, Byron J., and Mary-Jo DelVecchio Good

1993 Learning Medicine: The Construction of Medical Knowledge at Harvard Medical School. In Knowledge, Power, and Practice: The Anthropology of Medicine and Everyday Life. Shirley Lindenbaum and Margaret Lock, eds., pp 81-107. Berkeley: University of California Press.

Gordon, Deborah R.

1988 Tenacious Assumptions in Western Medicine. In Biomedicine Examined. Margaret Lock and Deborah R. Gordon, eds., pp 19-56. Boston: Kluwer.

Hafferty, Frederic W.

1988 Cadaver Stories and the Emotional Socialization of Medical Students. Journal of Health and Social Behavior 29(4): 344-356.

1991 Into the Valley: Death and the Socialization of Medical Students. New Haven: Yale University Press.

1998 Beyond Curriculum Reform: confronting Medicine's Hidden Curriculum. Academic Medicine 73(4): 403-407.

2000 Reconfiguring the Sociology of Medical Education: Emerging Topics and Pressing Issues. In Handbook of Medical Sociology. C.E. Bird, P. Conrad, and A.M. Fremont, eds., pp. 238-257. Upper Saddle River, NJ: Prentice Hall.

Hahn, Robert, and Arthur Kleinman

1983 Biomedical Practice and Anthropological Theory: frameworks and Directions. Annual Review of Anthropology 12: 305-333.

Klass, Perri

1987 A Not Entirely Benign Procedure: Four Years as a Medical Student. New York: Putnam.

Kleinman, Arthur

1980 Patients and Healers in the Context of Culture: An Exploration of the Borderland between Anthropology, Medicine, and Psychiatry. Berkeley: University of California Press.

Kleinman, Arthur, Veena Das, and Margaret Lock, eds.

1997 Social Suffering. Berkeley: University of California Press.

Konner, Melvin

1987 Becoming a Doctor: A Journey of Initiation in Medical School. New York: Viking. 
Lief, Harold I., and Renée C. Fox

1963 Training for "Detached Concern" in Medical Students. In The Psychological Basis of Medical Practice. Harold Lief, Victor Lief, and Nina Lief, eds., pp. 12-35. New York: Harper and Row.

Marion, Robert

1991 Learning to Play God: The Coming of Age of a Young Doctor. Reading, Massachusetts: Addison-Wesley Publishing Company, Inc.

Merton, R.K., G. Reader, and P.L. Kendall, eds.

1957 The Student Physician: Introductory Studies in the Sociology of Medical Education. Cambridge, MA: Harvard University Press.

Navarro, Vicente

1989 Radicalism, Marxism and Medicine. Medical Anthropology 11: 195-219.

Reilly, Phillip

1987 To Do No Harm: A Journey through Medical School. Dover, MA: Auburn House.

Rhodes, Lorna A.

1991 Emptying Beds: The Work of an Emergency Psychiatric Unit. Berkeley, CA: University of California Press.

Scheper-Hughes, Nancy, and Margaret M. Lock

1986 Speaking "Truth" to Illness: metaphors, Reification, and a Pedagogy for Patients. Medical Anthropology Quarterly 17(5): 137-140.

Singer, Merrill, and Hans Baer

1995 Critical Medical Anthropology. Amityville, NY: Baywood Publishing Company, Inc.

Taussig, Michael

1980 Reification and the Consciousness of the Patient. Social Science and Medicine 14B: 3-13.

Waitzkin, Howard

1986 Micropolitics of Medicine: Theoretical Issues. Medical Anthropology Quarterly 17(5): 134-136. 